\title{
Changes in kinesin expression in the CNS of mice with dynein heavy chain 1 mutation
}

\author{
Magdalena Kuźma-Kozakiewicz',3, Beata Kaźmierczak2,3, Ewa Usarek² \\ and Anna Barańczyk-Kuźma2,3凶
}

${ }^{1}$ Chair and Department of Neurology, ${ }^{2}$ Chair and Department of Biochemistry, ${ }^{3}$ Neurodegenerative Diseases Research Group, Medical University of Warsaw, Warsaw, Poland

Dysfunction of fast axonal transport, vital for motor neurons, may lead to neurodegeneration. Anterograde transport is mediated by N-kinesins (KIFs), while retrograde transport by dynein 1 and, to a minor extent, by C-kinesins. In our earlier studies we observed changes in expression of $\mathrm{N}$ - and C-kinesins (KIF5A, 5C, C2) in G93ASOD1-linked mouse model of motor neuron degeneration. In the present work we analyze the profile of expression of the same kinesins in mice with a dynein 1 heavy chain mutation (Dync1h1, called Cra1), presenting similar clinical symptoms, and in Cra1/SOD1 mice with milder disease progression than SOD1 transgenics. We found significantly higher levels of mRNA for KIF5A and KIF5C but not the KIFC2 in the frontal cortex of symptomatic Cra1/+ mice (aged 365 days) compared to the wild-type controls. No changes in kinesin expression were found in the spinal cord of any age group and only mild changes in the hippocampus. The expression of kinesins in the cerebellum of the presymptomatic and symptomatic mice (aged 140 and 365 days, respectively) was much lower than in age-matched controls. In Cra1/SOD1 mice the changes in KIFs expression were similar or more severe than in the Cra1/+ groups, and they also appeared in the spinal cord. Thus, in mice with the Dync1h1 mutation, which impairs dynein 1-dependent retrograde transport, expression of kinesin mRNA is affected in various structures of the CNS and the changes are similar or milder than in mice with double Dync1h1/hSOD1G93A mutations.

Key words: kinesins, expression, central nervous system, Dync1h1 mutation, Cra1/+ mice, Cra1/SOD1 mice

Received: 25 July, 2012; revised: 05 December, 2012; accepted: 21 February, 2013; available on-line: 05 March, 2013

\section{INTRODUCTION}

Kinesins (KIFs) form a superfamily of proteins involved in fast, long-distance axonal transport (Hirokawa et al., 2009). Since motor neurons are very large cells with axons reaching the length of over one meter in humans, kinesins are vital for their survival (El-Kadi et al., 2007). Kinesins are classified into 15 families and grouped as N-, M-, and C-kinesins according to their conserved motor domain position (Hirokawa et al., 2009; Kanai et al., 2000). The most abundant N-kinesins participate in the anterograde transport (from the cell body to the distal axon), whereas the less numerous C-kinesins, in the retrograde transport (in opposite direction) (Hirokawa et al., 2009; Hirokawa \& Tekamura, 2004; Saito et al., 1997; Kanai et al., 2000). The kinesins studied in the present work belong to the N-group (family 1 - KIF5A and KIF5C) and C-group (family 14B - KIFC2). They are tetrameric proteins comprising two heavy and two light chains. Their heavy chains show ATPase activity and are responsible for energy production and motor activity, whereas the light chains are responsible for cargo binding (Vale \& Fletterick, 1997; Hua et al., 1997). KIF5A and KIF5C are specific to neurons and essential for mitochondrial transport (Kanai et al., 2000). KIFC2 is present in neural cell bodies, axons and dendrites and seems to be involved in the transport of multivesicular body-like organelles, but its exact function is not clear (Hanlon et al., 1997; Saito et al., 1997). Beside the Ckinesins, the retrograde transport is maintained by cytoplasmic dynein 1 acting as a multi-protein complex with dynactin (Eschbach \& Dupuis, 2011; Vaughan, 2005). There is much indirect evidence for an involvement of cytoplasmic dynein 1 and dynactin in the pathogenesis of motor neuron diseases (Puls et al. 2003; Perlson, et al, 2010; Eschbach \& Dupuis, 2011; Ikenaka et al., 2012).

Among the motor neuron diseases (MND), amyotrophic lateral sclerosis (ALS) is the most frequent, devastating and fatal (Ince et al., 2011). ALS patients develop rapidly progressive paralyses of skeletal muscles leading to complete immobility and loss of autonomy. They die within three to five years from symptoms onset, usually due to respiratory failure. About $85 \%$ of ALS cases are sporadic (SALS) and the remaining 15\% are familial (FALS). Mutations in the SOD1 gene are responsible for about $20 \%$ of the genetically determined and up to $7 \%$ of SALS cases (Andersen, 2006; Mulder et al., 1986). Mice expressing human SOD1 gene with G93A mutation develop clinical symptoms similar to ALS in humans and are used as a classical model for studies of the disease (Gurney et al., 1994; Dal Canto \& Gurney, 1995; Tu et al.,1996). Defects in the retrograde transport appear in their motor neurons in early stages of embryonic development (Kieran et al., 2005). However, symptoms of motor neuron degeneration were also observed in mice with autosomal dominant missense point mutation in the gene encoding the heavy chains of cytoplasmic dynein 1 (Dync1h1). Those mice, called Cra1 due to cramping of the hindlimbs when suspended by tail, show a similar but milder phenotype to the SOD1G93A mice and have been considered as a new model for studies on motor neuron degeneration (Hafezparast et al., 2003; Teuchert et al., 2006). The retrograde axonal transport

e-mail: anna.kuzma@wum.edu.p

Abbreviations: KIF, kinesin; Dync1h1, heavy chain of cytoplasmic dynein 1; Cra1, cramping 1; hSOD1, human superoxide dismutase 1; CNS, central nervous system; ALS, amyotrophic lateral sclerosis; MND, motor neuron degeneration. 
mediated by the dynein/dynactin complex is impaired in Cra1 mice (Hafezparast et al., 2003; Hrabe de Angelis et al., 2000; LaMonte et al., 2002). Nevertheless, they show later onset of symptoms compared to the SOD1G93A mice and nearly normal life-span. Crossing the SOD1G93A with Cra1 mice slightly increases their life-span relative to that of SOD1G93A, but it is still shorter than for the Cra1 mice (Hafezparast et al., 2003; Kieran et al., 2005; Teuchert et al., 2006). Since in the double Cra1/ SOD1 heterozygotes the disease progression is delayed relative to SOD1G93A, the Dync1h1 mutation appears to slow down the motor neuron degeneration caused by the SOD1G93A toxicity (Kieran et al., 2005; Teuchert et al., 2006). However, the mechanism by which Dync1h1 mutation affects the phenotype of the SOD1 transgenics is not clear. In our recent work we showed several changes in the expression of N-kinesins (KIF5A, 5C) and C-kinesins (KIFC2/C3) in the CNS from both human SALS cases and mice with the G93A mutation in human SOD1 (Kuźma-Kozakiewicz et al., 2012). In the present work we continued the studies on Cra1/+ and Cra1/ SOD1 mice to find out whether the Dync1b1 mutation affects mRNA expression of kinesins involved in both anterograde and retrograde transport, and whether it has any influence on their mRNA expression in mice with the SOD1G93A mutation. We performed studies on brain frontal cortex and cervical spinal cord, the structures usually affected in ALS, and on the hippocampus, a structure not affected (control) by the disease. We also included the cerebellum, the CNS structure rarely studied in motor neuron degeneration (MND), because of a number of interesting features we had observed there previously (Barańczyk-Kuźma et al., 2007; Kaźmierczak et al., 2011; Kuźma-Kozakiewicz et al., 2012).

\section{MATERIALS AND METHODS}

Tissue dissection. Brain frontal cortex, hippocampus, spinal cord and cerebellum were obtained from mouse strain $\mathrm{C} 57 \mathrm{BL} / 6 \mathrm{GJ}-\mathrm{C} 3 \mathrm{H} / \mathrm{HeJ}$ (B6-C3H) hybrids harboring dynein heavy chain 1 mutation (Dync1h1; socalled Cra1/+), double Dync1h1/human SOD1G93A mutation (Cra1/SOD1), and from genetic backgroundand age-matched wild-type controls $(+/+$ ) (six males in each group). The SOD1G93A males (B6 background; Jackson Laboratories, Barr Harbor, ME, USA) were crossed with $\mathrm{Cra1} /+$ heterozygote female mice (C3He background; Ingenium Pharmaceuticals AG, Martinsried, Germany), as described by Teuchert et al. (2006). The transgenic mice were at the presymptomatic stage (age 70 days for Cra1/SOD1 and Cra1/+, and 140 days for

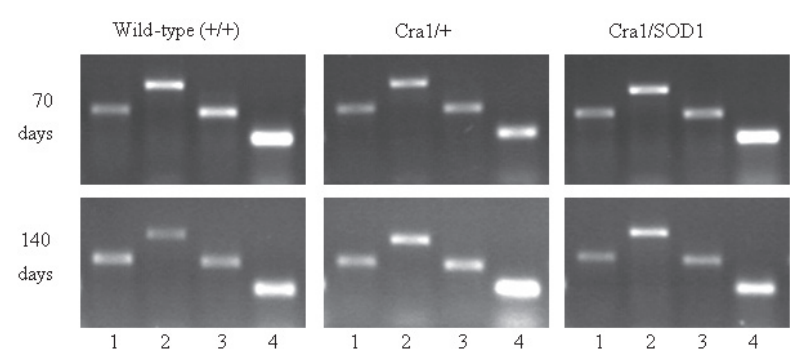

Figure 1. An example of kinesins expression in the frontal brain cortex.

The expression was studied by RT-PCR in mice aged 70 and 140 days, as described in Material and Method. The same amount of PCR product $(12.5 \mu \mathrm{l})$ was run in each lane. Lane 1, KIF5A; lane 2, KIF5C; lane 3, KIFC2; lane 4, S12 protein cDNA.
Cra1) or at the symptomatic stage (age 140 for Cra1/ SOD1 and 365 days for Cra1/+). Brain frontal cortex, cervical spinal cord, hippocampus and cerebellum were isolated immediately after the animals were sacrificed, stored at $-80^{\circ} \mathrm{C}$, and used in subsequent experiments.

Methods. Total RNA was isolated with the use of NucleoSpin ${ }^{\circledR}$ RNAII kit (Macherey-Nagel) according to manufacturer's protocol followed by reverse transcription, polymerase chain reaction and DNA electrophoresis in agarose gel. The reverse transcription reaction mixture contained $2 \mu \mathrm{g}$ of total RNA and $1 \mu \mathrm{l}$ of obtained cDNA were used as the substrate for PCR. Specific primers for mouse kinesins were as follows: for KIF5A - 5'GGATCGCTCGAGACATCTTC3' and 5'TCTGCTCGGTCTCTACGT'TC3', for KIF5C — 5'CATGGACGAGAACCTGGAGT3' and 5'GTCCTGGAGAATCCGAGTCA3', for KIFC2 — 5'ATGCGTCTTGCTGAGTTCCT3' and 5'CTCTGTTCCTCCTCCAACTG3'. The primers for ribosomal S12 protein cDNA (a housekeeping gene) were: 5'TCGCATCCAACTGTGATGAG3' and 5'TCT'TTGCCATAGTCCT'TAACCACTACG3'. For each pair of primers optimal conditions of the reaction were established, including $\mathrm{Mg}^{2+}$ ions, primers and dNTP concentration, temperature of annealing and number of reaction cycles. PCR reaction was carried out as follows: initial denaturation $\left(3 \mathrm{~min}\right.$ at $\left.94^{\circ} \mathrm{C}\right)$ followed by 20 (KIF5C), 24 (KIF5A) and 25 (KIFC2 and S12) cycles (denaturation for $1 \mathrm{~min}$ at $94^{\circ} \mathrm{C}$, annealing for $30 \mathrm{~s}$ at $55^{\circ} \mathrm{C}$ for kinesins and $60^{\circ} \mathrm{C}$ for $\mathrm{S} 12$, extension for $2 \mathrm{~min}$ at $72^{\circ} \mathrm{C}$ ) and a final extension step ( $7 \mathrm{~min}$ at $72^{\circ} \mathrm{C}$ ). PCR products were separated on $1.5 \%$ agarose gel with ethidium bromide $(0.5 \mu \mathrm{g} / \mu \mathrm{l})$. The relative kinesin mRNA levels were expressed as the ratio of the optical density value of each kinesin band to the optical density of the S12 band. Each assay was performed in duplicate and repeated two times. System UVI-KS4000 (Syngen Biotechnology) was used for densitometric analysis. Results were expressed as means \pm S.D., and the data were analyzed by the two-way analysis of variance (ANOVA). Quantitative comparison between studied groups was performed by Student's $t$-test using Statistica 9.0 (StatSoft). The level of significance was set at $p<0.05$. Studies were approved by the Ethics Committee for Experiments on Animals at the Medical University of Warsaw (AO-KEZ/622/3).

\section{RESULTS}

Results on kinesin expression in the wild-type, Cra1/+ and Cra1/SOD1 mice, at various age/clinical stage are shown in Table 1 . In the frontal cortex of the wild-type mice, the level of KIF5A expression was independent of age, whereas that of KIF5C and C2 was significantly higher in younger (aged 70 days) than in older animals $(p<0.00001$ for KIF5A, $p<0.001$ and $p<0.01$ for KIFC2 in mice aged 140 and 365 days, respectively). There were no age-related changes in the hippocampus and the spinal cord of the wild-type mice, but in the cerebellum the entire kinesin expression was significantly lower in 70-day-old mice than in older animals $(p<0.0002$ and $p<0.01$ for KIF5A in mice aged 140 and 365 days, respectively; $\mathrm{p}<0.01$ for KIF5C in mice aged 140 days; $p<0.00001$ and $p<0.002$ for KIFC2 in mice aged 140 and 365 days, respectively).

In the frontal cortex of Cra1/+ mice a significant increase of KIF5A expression occurred at the symptomatic (mice aged 365 days; $p<0.0001$ ) but not at the presymptomatic stage (aged 70 and 140 days) compared to wild- 
Table 1. Expression of kinesins in various structures of mice CNS

\begin{tabular}{|c|c|c|c|c|}
\hline KIF & Age, days & Wild-type $(+/+)$ & Cra1/+ & Cra1/SOD1 \\
\hline \multicolumn{5}{|c|}{ Frontal cortex } \\
\hline $5 A$ & $\begin{array}{l}70 \\
140 \\
365\end{array}$ & $\begin{array}{l}0.17 \pm 0.03 \\
0.18 \pm 0.05 \\
0.19 \pm 0.03\end{array}$ & $\begin{array}{l}0.17 \pm 0.04 \\
0.23 \pm 0.08 \\
0.25 \pm 0.03^{b}\end{array}$ & $\begin{array}{l}0.16 \pm 0.02 \\
0.20 \pm 0.04 \\
-\end{array}$ \\
\hline $5 C$ & $\begin{array}{l}70 \\
140 \\
365\end{array}$ & $\begin{array}{l}0.35 \pm 0.07 \\
0.19 \pm 0.04^{a} \\
0.19 \pm 0.04^{a}\end{array}$ & $\begin{array}{l}0.20 \pm 0.09^{b} \\
0.23 \pm 0.04^{b} \\
0.29 \pm 0.04^{b}\end{array}$ & $\begin{array}{l}0.31 \pm 0.05 \\
0.49 \pm 0.13^{b} \\
-\end{array}$ \\
\hline $\mathrm{C} 2$ & $\begin{array}{l}70 \\
140 \\
365\end{array}$ & $\begin{array}{l}0.27 \pm 0.04 \\
0.22 \pm 0.05^{a} \\
0.23 \pm 0.04^{a}\end{array}$ & $\begin{array}{l}0.20 \pm 0.08^{b} \\
0.22 \pm 0.08 \\
0.26 \pm 0.04\end{array}$ & $\begin{array}{l}0.21 \pm 0.03^{b} \\
0.28 \pm 0.08^{b} \\
-\end{array}$ \\
\hline \multicolumn{5}{|c|}{ Spinal cord } \\
\hline $5 A$ & $\begin{array}{l}70 \\
140 \\
365\end{array}$ & $\begin{array}{l}0.12 \pm 0.01 \\
0.13 \pm 0.02 \\
0.13 \pm 0.02\end{array}$ & $\begin{array}{l}0.13 \pm 0.01 \\
0.17 \pm 0.05 \\
0.15 \pm 0.04\end{array}$ & $\begin{array}{l}0.19 \pm 0.04^{b} \\
0.16 \pm 0.02^{b}\end{array}$ \\
\hline $5 C$ & $\begin{array}{l}70 \\
140 \\
365\end{array}$ & $\begin{array}{l}0.19 \pm 0.03 \\
0.18 \pm 0.01 \\
0.18 \pm 0.02\end{array}$ & $\begin{array}{l}0.17 \pm 0.02 \\
0.16 \pm 0.03 \\
0.18 \pm 0.02\end{array}$ & $\begin{array}{l}0.23 \pm 0.03^{b} \\
0.21 \pm 0.06\end{array}$ \\
\hline $\mathrm{C} 2$ & $\begin{array}{l}70 \\
140 \\
365\end{array}$ & $\begin{array}{l}0.15 \pm 0.02 \\
0.13 \pm 0.02 \\
0.12 \pm 0.02\end{array}$ & $\begin{array}{l}0.14 \pm 0.01 \\
0.14 \pm 0.04 \\
0.15 \pm 0.03\end{array}$ & $\begin{array}{l}0.17 \pm 0.03 \\
0.15 \pm 0.01^{b} \\
-\end{array}$ \\
\hline \multicolumn{5}{|c|}{ Hippocampus } \\
\hline $5 A$ & $\begin{array}{l}70 \\
140 \\
365\end{array}$ & $\begin{array}{l}0.15 \pm 0.02 \\
0.13 \pm 0.02 \\
0.13 \pm 0.02\end{array}$ & $\begin{array}{l}0.17 \pm 0.02^{b} \\
0.12 \pm 0.04 \\
0.14 \pm 0.02\end{array}$ & $\begin{array}{l}0.14 \pm 0.02 \\
0.15 \pm 0.02^{b} \\
-\end{array}$ \\
\hline $5 C$ & $\begin{array}{l}70 \\
140 \\
365\end{array}$ & $\begin{array}{l}0.21 \pm 0.03 \\
0.20 \pm 0.06 \\
0.21 \pm 0.03\end{array}$ & $\begin{array}{l}0.18 \pm 0.03^{b} \\
0.20 \pm 0.04 \\
0.23 \pm 0.02\end{array}$ & $\begin{array}{l}0.19 \pm 0.02^{b} \\
0.24 \pm 0.03 \\
-\end{array}$ \\
\hline $\mathrm{C} 2$ & $\begin{array}{l}70 \\
140 \\
365\end{array}$ & $\begin{array}{l}0.17 \pm 0.02 \\
0.11 \pm 0.01 \\
0.14 \pm 0.02\end{array}$ & $\begin{array}{l}0.16 \pm 0.02 \\
0.15 \pm 0.07 \\
0.18 \pm 0.03^{b}\end{array}$ & $\begin{array}{l}0.13 \pm 0.02^{b} \\
0.19 \pm 0.04^{b} \\
-\end{array}$ \\
\hline \multicolumn{5}{|c|}{ Cerebellum } \\
\hline $5 A$ & $\begin{array}{l}70 \\
140 \\
365\end{array}$ & $\begin{array}{l}0.19 \pm 0.04 \\
0.28 \pm 0.05^{a} \\
0.24 \pm 0.06^{a}\end{array}$ & $\begin{array}{l}0.19 \pm 0.02 \\
0.18 \pm 0.06^{b} \\
0.15 \pm 0.02^{b}\end{array}$ & $\begin{array}{l}0.18 \pm 0.03 \\
0.21 \pm 0.08^{b} \\
-\end{array}$ \\
\hline $5 C$ & $\begin{array}{l}70 \\
140 \\
365\end{array}$ & $\begin{array}{l}0.21 \pm 0.03 \\
0.27 \pm 0.07 a \\
0.24 \pm 0.05\end{array}$ & $\begin{array}{l}0.23 \pm 0.08 \\
0.19 \pm 0.07 b \\
0.21 \pm 0.04\end{array}$ & $\begin{array}{l}0.24 \pm 0.04 \\
0.25 \pm 0.10\end{array}$ \\
\hline $\mathrm{C} 2$ & $\begin{array}{l}70 \\
140 \\
365\end{array}$ & $\begin{array}{l}0.15 \pm 0.03 \\
0.27 \pm 0.05^{a} \\
0.20 \pm 0.05^{a}\end{array}$ & $\begin{array}{l}0.15 \pm 0.02 \\
0.17 \pm 0.05^{b} \\
0.12 \pm 0.02^{b}\end{array}$ & $\begin{array}{l}0.15 \pm 0.03 \\
0.21 \pm 0.08 \mathrm{~b} \\
-\end{array}$ \\
\hline
\end{tabular}

The expression was quantitated by RT-PCR, as described in Materials and methods. The results are expressed as the ratio of the optical density for each kinesin to the optical density of the S12 cDNA band. Each value is the mean \pm S.D. of 2 experiments performed in duplicate. aDifference statistically significant when compared to 70-day-old wild-type mice; bdifference statistically significant when compared to the age-matched control.

type controls. In Cra1/SOD1 hybrids KIF5A expression was unchanged (Table 1). Kinesin 5C expression in 70-day old Cra1/+ mice was significantly lower than in the age-matched control $(p<0.001)$ but in the older groups, both presymptomatic (aged 140 days) and symptomatic (aged 365 days), it was significantly higher than in the wild-type mice $(p<0.05$ and $p<0.0001$, respectively). In Cra1/SOD1 hybrids KIF5C expression was unchanged in the presymptomatic mice and increased at the symptomatic stage $(p<0.0001)$. KIFC2 expression in both Cra1/+ and Cra1/SOD1 70-day- old transgenics was lowered when compared with the control groups $(p<0.01$ and $p<0.0001$, respectively). In older Cra1/+ mice (aged 140 and 365 days) it was unchanged but in Cra1/SOD1 significantly increased $(p<0.005)$ (Table 1$)$.

In the spinal cord of $\mathrm{Cra1} /+$ mice the expression of studied kinesins in all animal groups was unchanged (Table 1). In Cra1/SOD1 mice KIF5A expression was significantly increased compared to the wild-type controls, at both presymptomatic (aged 70 days) and symptomatic stages (aged 140 days) $(p<0.0001$ and $p<0.005$, respectively), whereas that of KIF5C and C2 was slightly increased only at the presymtomatic stage $(p<0.05)$ (Table 1).

In the hippocampus of $\mathrm{Cra1} /+$ mice, KIF5A expression was higher $(p<0.01)$, KIF5C lower $(p<0.01)$ in the 70 -day-old-presymptomatic group compared to the agematched controls, and KIFC2 expression was significantly decreased in the group aged 365 days $(p<0.005)$ (Table 1). In the double Cra1/SOD1 hybrids, KIF5A expression was slightly higher at the symptomatic stage $(p<0.05)$, KIF5C slightly lower at the presymptomatic $(p<0.05)$ than in the control groups, and KIFC2 was changed at both stages - decreased at the presymptomatic $(p<0.001)$ but increased at the symptomatic stage $(p<0.0001)$.

In the cerebellum of Cra1/+ transgenics, differently than in other structures of the CNS, expression of all 
KIFs was lowered in the older groups (aged 140 and 365 ) but not in the younger one (aged 70 days) (Table 1). The decrease was significant for KIF5A with $p<0.001$ in mice aged 140 days and $p<0.0001$ in mice aged 365 days. The changes in KIF5C expression occurred in both age groups, however they were significant only in 140-day-old mice $(\mathrm{p}<0.005)$. KIFC2 expression was significantly decreased in both groups $(p<0.0001)$. In Cra1/SOD1 transgenics expression of KIF5A and KIFC2 was lowered at the symptomatic stage (aged 140 days, $p<0.005$ and $p<0.05$, respectively) but KIF5C was unchanged.

Anova analysis showed that in the frontal cortex expression of KIF5C and KIFC2 but not KIF5A was dependent on both mutation and age/clinical stage with $\mathrm{F}(3.98)=38.607, p=0.00001$, and $\mathrm{F}(3.10)=8.754$, $p=0.0001$, respectively. In the spinal cord, only KIF5A expression was dependent on both mutation and age/ clinical stage $(\mathrm{F}(3.71)=3.295, p=0.0253)$. In the hippocampus, the expression of all kinesins was dependent on mutation and clinical stage (age) with $\mathrm{F}(3.79)=6.459$, $p=0.0006, \mathrm{~F}(3.78)=5.087, p=0.0029)$, and $\mathrm{F}(3.79)=10.766$, $p=0.00001$ for KIF5A, KIF5C and KIFC2, respectively. In the cerebellum expression of KIF5A $(\mathrm{F}(3.95)=4.541$, $p=0.0051)$ and KIFC2 $(\mathrm{F}(3.97)=4.369, p=0.0063)$ was dependent on mutation and clinical stage.

\section{DISCUSSION}

Because of difficulties in obtaining human tissues and the variability of clinical manifestations in ALS patients, many studies on the pathogenesis of motor neuron degeneration (MND) are conducted on animal models. The most popular, classical model of MND are mice harboring the SOD1G93A mutation (Gurney et al., 1994). Studies published in the last decade have shown that also mice with cytoplasmic dynein 1 mutations (Cra1, Loa) develop a late onset MND (Hafezparast et al., 2003; Kieran, et al. 2005; Teuchert et al., 2006).

The molecular mechanisms of Dync1h1-linked neuronal pathology and degeneration are still unclear and point to an involvement of either alpha motor neurons or/and peripheral nerves. Also the cause of the increased life-span of the double Dync1h1/SODG93A mice as compared to $\mathrm{SOD} 1 /+$ mice remains vague.Therefore we undertook studies aimed to shed more light on the impairment of the transport processes in the cortex (corticospinal tracts) and the spinal cord (including alphamotor neurons).

Studying expression of kinesins in the CNS of mice with human SOD1G93A mutation we found a significant increase of KIF5A, 5C and C2 levels in the frontal cortex of symptomatic animals (Kuźma-Kozakiewicz et al., 2012). In Cra1/+ mice, studied in the present work, the expression of kinesins involved in the anterograde transport (KIF5A and 5C) but not in the retrograde transport (KIFC2) was raised. Similarly to SOD1/+ mice, KIFC2 expression was significantly increased in symptomatic Cra1/SOD1 hybrids.

In the spinal cord of SOD1/+ mice the KIF5A expression was increased at both pre- and symptomatic stages, while the KIFC2 expression - at the symptomatic stage only (Kuźma-Kozakiewicz et al., 2012). In $\mathrm{Cra1} /+$ mice the expression of all kinesins was unchanged. In this structure the expression of all kinesins was much lower than in the frontal cortex, in both wild-type and Cra1/+ mice. This disproportion could explain the lack of visible changes in the spinal cord.
However, the level of kinesins expression in the spinal cord of $\mathrm{Cra1} /+$ mice was comparable to that found in SOD1/+ transgenics, where the changes were well seen. They were also observed in Cra1/SOD1 mice. This indicates that the spinal cord might not be affected by the Dync1h1 mutation.

In the hippocampus, not affected in MND, the expression of kinesins was unchanged in SOD1/+ mice (Kuźma-Kozakiewicz et al., 2012), with minor changes in their expression in Cra1/+ and Cra1/SOD1 transgenics.

Despite the lack of cerebellar signs in patients with ALS, we observed several changes of kinesin expression in both SOD1/+ and Cra1/+ mice in the cerebellum. Surprisingly, the changes were opposite to the ones found in other CNS structures. In SOD1/+ mice, the expression of all studied KIFs was significantly decreased at the symptomatic stage (Kuźma-Kozakiewicz et al., 2012), whereas in Ca1/+ mice the decrease was observed earlier, at the presymptomatic stage (age 140 days) and lasted through the symptomatic stage (age 365 days). In $\mathrm{Cra} 1 / \mathrm{SOD} 1$ mice the expression was unchanged (KIF5C) or lower than in the wild-type controls.

The KIF expression was not the only molecular feature which differed between the Cra1/+ and SOD1/+ mice. Kinesins transport their cargo using microtubules that form intracellular tracts stabilized by tau protein. Tau effectively participates in the axonal transport being also involved in microtubule polymerization, organization into bundles, and interaction with dynein/dynactin complexes (Hirokawa et al., 1988; Magnani et al., 2007). Our earlier studies on tau expression and its alternative splicing in SOD1G93A and Cra1/+ mice showed clear differences between these two transgenic models (KuźmaKozakiewicz et al., 2011). The disturbances of tau expression, especially in the frontal cortex and cerebellum, were more severe in mice with the SOD1G93A than with the Dync1h1 mutation (Kuźma-Kozakiewicz et al., 2011). Studying glutathione S-transferase pi, an enzyme involved in detoxification of electrophilic compounds and products of oxidative stress, we found that its expression was decreased in the frontal cortex, hippocampus and spinal cord of SOD1/+ but not Cra1/+ mice (Kaźmierczak et al., 2011). Dissimilarities between the two models have also been seen by other groups. Contrary to the first Cra1 description by Hafezparast et al. (2003), Courchesne et al. (2011) did not confirm a significant loss of primary motor neurons at their symptomatic stage. They showed instead a decreased complexity of neuromuscular junctions. According to those authors, the clinical symptoms of Cra1/+ mice were associated with muscle fiber abnormalities rather than with neurodegeneration. Dupuis et al. (2009) did not observe electrophysiological or biochemical signs of muscle denervation indicative of motor neuron disease in the Cra1/+ heterozygotes. In their opinion, the Cra1 phenotype could be related to a prominent degeneration of sensory neurons associated with a loss of muscle spindles. The Dync1h1-linked symptoms could therefore lead to a mild peripheral neuropathy rather than to motor neuron disease. Taken together, these data indicate that despite some similarities in the phenotype, Cra1 mice should not be used as an animal model of motor neuron degeneration.

The changes we observed in kinesin expression in the Cra1/SOD1 hybrids, especially in the frontal cortex and the spinal cord, partially varied from those of Cra1/+ mice and were similar to but milder than those of the SOD1/+ transgenics. They were less pronounced than in mice with a single mutation, either Dync1h1 or SOD1G93A (Kuźma-Kozakiewicz et al., 2012). Thus, 
the Dync1h1 mutation influences kinesins expression in $\mathrm{SOD} 1 /+$ mice, but its mechanism remains unclear.

The expressin of kinesins in wild-type mice was much higher in the brain frontal cortex and cerebellum than in the spinal cord and hippocampus. In the frontal cortex, the expression of KIF5C and C2 (but not 5A) was age-dependent and was significantly lower in groups aged 140 and 365 days comparing to the 70-day-old one. It was accompanied by a lower tau expression in old (aged 365 days) compared to young (aged 70 days) mice (Barańczyk-Kuźma et al., 2007) indicating an impairment in axonal transport with age. On the other hand, the increased kinesin mRNA expression in the frontal cortex of older Cra1/+ and Cra1/SOD1 mice could indicate a compensatory mechanism to restore axonal transport affected by both age and mutation.

In the cerebellum of wild-type animals, the expression of all kinesins investigated was higher in the older groups. A possible mechanism may be a compensatory response to the age-related disturbances in other proteins involved in axonal transport, such as a decreased dynactin expression in old wild-type but not Cra1/+ or Cra1/SOD1 mice (unpublished data).

It can be concluded that in mice with the Dync1h1 mutation, which impairs dynein 1-dependent retrograde transport, expression of kinesin-mRNA is affected in various structures of the CNS and the changes are similar to or milder than in mice with double Dync1h1/ hSOD1G93A mutations.

\section{Acknowledgements}

This study was supported by grants N N401 417436 and N N401 063436 from the Ministry of Science and Higher Education of Poland.

The Authors would like to thank Prof. Albert C. Ludolph and Dr. Birgit Schwalenstöcker from the University of Ulm, Germany for providing tissues from transgenic mice.

\section{REFERENCES}

Andersen P (2006) Amyotrophic lateral sclerosis associated with mutations in the CuZn superoxide dismutase gene. Current Neurol Neurosci Rep 6: 37-46.

Barańczyk-Kuźma A, Usarek E, Kuźma-Kozakiewcz M, Kaźmierczak B, Gajewska B, Schwalenstocker B, Ludolph AC (2007) Age-related changes in tau expression in transgenic mouse model of amyotrophic lateral sclerosis. Neurochem Res 32: 415-421.

Coleman M (2005) Axon degeneration mechanisms: commonality amid diversity. Nat Rev Neurosci 6: 889-898.

Courchesne SL, Pazyra-Murphy MF, Lee DJ, Segal RA (2011) Neuromuscular junction defects in mice with mutation of dynein heavy chain 1. PLoS One. 4; 6: e16753.

Dal Canto MC, Gurney ME (1995) Neuropathological changes in two lines of mice carrying a transgene for mutant human CuZn SOD and in mice overexpressing wild type human SOD: a model of familial amyotrophic lateral sclerosis. Brain Res 676: 25-40.

Dupuis L, Fergani A, Braunstein KE, Eschbach J, Holl N, Rene N, Gonzalez De Aguilar JL, Zoerner B, Schwalenstocker B, Ludolph AC, Loeffler JP (2009) Mice with a mutation in the dynein heavy chain 1 gene display sensory neuropathy but lack motor neuron disease. Exp Neurol 215: 146-152.

El-Kadi AM, Soura V, Hafezparast M (2007) Defective axonal transport in motor neurodiseas. I Neurosc Res 85: 2557-2566.

Eschbach J, Dupuis L (2011) Cytoplasmic dynein in neurodegeneration. Pharmacol Therapeut 130: 348-363.

Gurney ME, Pu H, Chiu AY, Dal Canto MC, Polchow CY, Alexander DD (1994) Motor neuron degeneration in mice that express a human $\mathrm{Cu}, \mathrm{Zn}$ superoxide dismutase mutation. Science 264: 1772-1775.

Hafezparast M, Klocke R, Ruhrberg C, Marquardt A, Ahmad-Annuar A , Bowen S, Lalli G, Witherden AS, Hummerich $H$, Nicholson S, Morgan PJ, Oozageer R, Priestley JV, Averill S, King RV, Ball S, Peters J, Toda T, Yamamoto A, Hiraoka Y, Augustin M, Korthaus D, Wattler S, Wabnitz P, Dickneite C, Lampel S, Boehme G, Peraus G, Popp A, Rudelius M, Schlegel J, Fuchs H, Hrabe de Angelis
M, Schiavo DT, Shima G, Russ AP, Stumm G, Martin JE, Fisher EM (2003) Mutations in dynein link motor neuron degeneration to defects in retrograde transport. Science 300: 808-881.

Hanlon DW, Yang Z, Goldstein LS (1997) Characterization of KIFC2, a neuronal kinesin superfamily member in mouse. Neuron 18: 439_ 451.

Hirokawa N, Shiomura Y, Ogabe S (1988) Tau proteins: the molecular structure and mode of binding on microtubules. I Cell Biol 107: 1449-1459.

Hirokawa N, Tekamura R (2004) Molecular motors in neuronal development, intracellular transport and diseases. Cur Op Neurol 14: 564-573

Hirokawa N, Noda Y, Tanaka Y, Niwa S (2009) Kinesin superfamily motor proteins and intracellular transport. Nature 10: 682-696.

Hrabe de Angelis $\mathrm{MH}$, Flaswinkel $\mathrm{H}$, Fuchs $\mathrm{H}$, Rathkolb B, SoewartoD, Marschall S, Heffner S, Pargent W, Wuensch, K Jung M, Reis A, Richter T, Alessandrini F, Jakob T, Fuchs E, Kolb H, Kremmer E, Schaeble K, Rollinski B, Roscher A, Peters C, Meitinger T, Strom T, Steckler T, Holsboer F, Klopstock T, Gekeler F, Schindewolf C, Jung TM, Avraham K, Behrendt H, Ring J, Zimmer A, Schughart K, Pfeffer K, Wolf E, Balling R (2000) Genome-wide, large-scale production of mutant mice by ENU mutagenesis. Nat Genet 25: 444-447.

Hua W, Young EC, Fleming ML, Gelles J (1997) Coupling of kinesin steps to ATP hydrolysis. Nature 388: 390-393.

Ikenaka K, Katsuno M, Kawai K, Ishigaki S, Tanaka F, Sobue G (2012) Disruption of axonal transport in motor neuron diseases. Int J Mol Sci 13: 1225-1238.

Ince PG, Highley JR, Kirby J, Wharton SB, Takahashi H, Strong MJ, Shaw PJ (2011) Molecular pathology and genetic advances in amyotrophic lateral sclerosis: an emerging molecular pathway and the significance of glial pathology. Acta Neuropathol 122: 657-671.

LaMonte BH, Wallace KE,. Holloway BA, Shelly SS, Ascaño J, Tokito M, Van Winkle T, Howland DS, Holzbaur EL (2002) Disruption of dynein/dynactin inhibits axonal transport in motor neurons causing late-onset progressive degeneration. Neuron 34: 715-727.

Kanai Y, Okada Y, Tanaka Y, Harada A, Terada S, Hirokawa N (2000) KIF5C, a novel neuronal kinesin enriched in motor neurons. I Neurosci 20: 6374-6384.

Kieran D, Hafezparast M, Bohnert S, Dick JR, Martin J, Schiaro G (2005) A mutation in dynein rescues axonal transport defect and extends the life span of ALS mice. I Cell Biol 169: 561-567.

Kaźmierczak B, Kuźma-Kozakiewicz M, Usarek, Barańczyk-Kuźma A (2011) Differences in glutathione S-transferase pi expression in transgenic mice with symptoms of neurodegeneration. Acta Biochim Pol 58: 621-626.

Kuźma-Kozakiewicz M, Usarek E, Ludolph AC, Barańczyk-Kuźma A (2011) Mice with mutation in dynein heavy chain 1 do not share the same tau expression pattern with mice with SOD1-related motor neuron disease. Neurochem Res 36: 978-985.

Kuźma-Kozakiewicz M., Chudy A, Gajewska B, Dziewulska D, Usarek E, Barańczyk-Kuźma A (2012) Kinesins expression in the central nervous system of humans and transgenic hSOD1G93A mice with amyotrophic lateral sclerosis. Neurodegenerative Dis online 21 Sept. 2012, DOI: $10.1159 / 000339529$.

Magnani E, Fan J, Gasparini L, Golding M et al. (2007) Interaction of tau protein with the dynactin complex. EMBO J 26: 4546-4554.

Mulder DW, Kurland LT, Offord KP, Beard CM (1986) Familial adult motor neuron disease: amyotrophic lateral sclerosis. Neurology 36: $511-517$

Nicotera P, Lipton SA (1999) Excitotoxins in neuronal apoptosis and necrosis, I Cereb. Blood Flow Metab. 19: 583-591.

Perlson E, Maday S,. Fu MM, Moughamian AJ, Holzbaur ELF (2010) Retrograde 414 axonal transport: pathways to cell death. Trends Neurosci 33: 335-344.

Puls I., Jonnakuty C., LaMonte BH, Holzbaur EL, Tokito M, Mann E, Floete MK, Bidus K, Drayna D, Oh SJ, Brown RH, Ludlow CL, Fischbeck KH.(2003) Mutant dynactin in motor neuron disease. Nat Genet 33: 455-456.

Saito N, Okada Y, Noda Y, Kinoshita Y, Kondo S, Hirokawa N (1997) KIFC2 is a novel neuron-specific C-terminal type kinesin superfamily motor for dendritic transport of multivesicular body-like organelles. Neuron 3: 425-438.

Teuchert M, Fischer D, Schwalenstoecker B, Habisch HJ, Bockers TM, Ludolph AC (2006) A dynein mutation attenuates motor neuron degeneration in SOD1G93A mice. Exp Neurol 98: 271-274.

Tu PH, Raju P, Robinson KA, Gurney ME, Trojanowski JQ, Lee VM (1996) Transgenic mice carrying a human mutant superoxide dismutase transgene develop neuronal cytoskeletal pathology resembling human amyotrophic lateral sclerosis lesions. Proc Nat Acad Sci USA 93: 3155-3160.

Vaughan KT (2005) Microtubule plus ends, motors, and traffic of Golgi membranes. Biochim Biophys Acta 1744: 316-324.

Vale RD, Fletterick RJ (1997) The design plan of kinesin motors. Ann Rev Cell Dev Biol 13: 745-777. 